\title{
Does electrocardiogram help in identifying the culprit artery when angiogram shows both right and circumflex artery disease in inferior myocardial infarction?
}

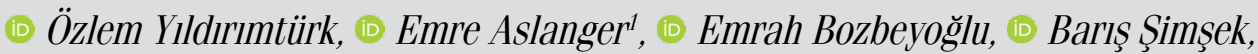 \\ (D) Mustafa Aytek Şimşek ${ }^{1}$, (D) Yusuf Sinan Aydın, (ㄷ) Can Yücel Karabay, (D) Muzaffer Murat Değertekin ${ }^{1}$
}

Department of Cardiology, Dr. Siyami Ersek Thoracic and Cardiovascular Surgery Training and Research Hospital; İstanbul-Turkey ${ }^{1}$ Department of Cardiology, Faculty of Medicine, Yeditepe University Hospital; İstanbul-Turkey

\section{ABSTRACT}

Objective: In a subgroup of patients with inferior myocardial infarction (MI), both the right coronary artery (RCA) and circumflex coronary artery (Cx) show potentially culprit lesions, and angiography may be insufficient to determine which artery is responsible for the clinical presentation. Although many electrocardiographic (ECG) algorithms have been proposed for identifying the infarct-related artery in patients with inferior MI, it is unclear whether the current algorithms have the discriminative power to identify the real culprit artery in these patients.

Methods: The patients with the diagnosis of acute inferior MI and underwent coronary angiography were enrolled in the study. The prediction of the infarct-related artery was attempted from the admission ECG using published algorithms and criteria. For the angiographic definition of the infarct-related artery, multiple criteria were used.

Results: Total 417 inferior MI cases were enrolled during the study period; the final patient population comprised of 318 patients. Forty-five patients $(14.2 \%)$ had both RCA and Cx lesions on coronary angiography. Although several criteria and algorithms are able to identify the infarct-related artery in the general inferior MI population, they lose their strength in patients with both RCA and Cx lesions. Only the Aslanger-Bozbeyoğlu criterion emerges as a more powerful diagnostic test with a sensitivity, specificity, and c-statistic of $80 \%, 48 \%$, and 0.650 , respectively for the whole population $(p<0.001)$ and $81 \%, 58 \%$, and 0.709 , respectively, for patients with both RCA and Cx lesions $(p=0.019)$.

Conclusion: The Aslanger-Bozbeyoğlu criterion is not only helpful in differentiating the infarct territory in combined inferior and anterior STsegment elevation as previously shown, but also valuable in identifying the infarct-related artery in patients with inferior STEMI with critical lesions in both the RCA and the Cx. (Anatol J Cardiol 2020; 23: 318-23)

Keywords: coronary occlusion, electrocardiogram, infarct-related artery, myocardial infarction, ST-segment elevation

\section{Introduction}

The prediction of the infarct-related artery on the basis of the admission electrocardiogram (ECG) in ST-segment elevation myocardial infarction (STEMI) is relevant and critical because it can anticipate specific mechanical complications, impending hemodynamic derangement, shock, and death $(1,2)$. Accordingly, many algorithms have been developed to identify the infarct-related artery and the occlusion site, especially in cases of inferior STEMI (3-19). However, after primary percutaneous coronary intervention (pPCI) became widely available and the preferred strategy for revascularization, many patients with STEMI are now being transferred to the catheterization laboratory before their admission ECG is examined to identify the possible culprit lesion. One unfortunate and common scenario is that wherein both the right coronary artery (RCA) and circumflex coronary artery (Cx) may show potentially culprit lesions in a patient brought to the catheterization laboratory because of inferior STEMI. Targeting the real culprit lesion is of utmost importance; however, sometimes, the angiographic appearance may be insufficient for guiding the interventionalist in this regard. Although ECG algorithms may be helpful, it is unclear whether the current algorithms have the discriminative power to identify the real culprit lesion in patients with critical stenosis in both the coronary arteries that supply the same myocardial territory. In this study, we aimed to compare algorithms proposed for the identification of the infarct-related artery in patients presenting with inferior STEMI and both $\mathrm{Cx}$ and RCA lesions.

Address for correspondence: Dr. Emre Aslanger, Yeditepe Üniversitesi Tıp Fakültesi Hastanesi, Kardiyoloji Anabilim Dalı, Hastaneyolu Sok., No: 4/4-1, İstanbul-Türkiye

Phone: +90 5325109796 E-mail: mr_aslanger@hotmail.com

Accepted Date: 21.02.2020 Available Online Date: 09.04.2020 


\section{Methods}

The study was undertaken at Dr. Siyami Ersek Cardiovascular and Thoracic Surgery Training and Research Hospital, Istanbul, that has a large transfer network with around 1500 STEMI patients per year being referred for $\mathrm{pPCl}$. The Institutional Review Board approved the study, and the trial was judged to be exempt from formal evaluation because it only involved the analyses of existing records. All patients who were admitted with the diagnosis of acute inferior STEMI and underwent coronary angiography that revealed an acute culprit lesion on the RCA, the Cx, or their branches from May 2017 to January 2018 were enrolled. Patients with a history of coronary artery bypass grafting, left bundle branch block, or any other secondary repolarization abnormality were excluded. Baseline characteristics were obtained via chart review.

All the electrocardiograms were reviewed by a cardiologist (E.A.) who was blinded to the angiographic and clinical outcomes. In patients with multiple ECGs, the earliest ECG with maximum ST-segment deviation was used. ST-segment elevation was measured at 60 milliseconds after the J-point and approximated to closest $0.5 \mathrm{~mm}$. The reviewer attempted to identify the infarct-related artery using 12-lead information according to the published algorithms and criteria (3-19), including the presence of ST-segment elevation in at least one lateral lead with an isoelectric or elevated ST-segment in lead I for the $\mathrm{Cx}(3)$, the presence of ST-segment depression in leads I and aVL for the RCA (4), the higher ST-segment elevation in lead III than in lead II and the greater ST-segment depression in lead aVL than in lead I for the RCA $(5,9,12)$, the presence of ST-segment depression in leads V1 or V2 for the Cx (6), the presence of ST-segment elevation in lead III exceeding that of lead II with ST-segment elevation in lead V1 for the RCA (7), the presence of ST-segment depression in aVR for the $\mathrm{Cx}$ $(10,15)$, Fiol's algorithm (ST-segment depression in lead I, STsegment elevation in lead III higher than that in lead II, and the sum of ST-segment depression in V1 to V3 less than the sum of ST-segment elevation in the inferior leads for the RCA) (11), Tierala's algorithm (ST-segment elevation in lead III higher than that in lead II, ST-segment elevation in V1, or isoelectric ST-segment segment in V1 but ST-segment depression in V2, ST-segment depression in aVR lower than that in lead aVL for the RCA) (13), Almansori's scoring system for the RCA ( $\geq 1)(14)$, Huang's algorithm (ST-segment elevation in lead III higher than that in lead II, ST-segment depression in lead I lower than that in aVL, ST-segment elevation $<0.5 \mathrm{~mm}$ in lead I for the RCA) (17), Ruiz-Mateos' formula (the sum of ST-segment elevation in lead III, aVF and V3 minus the sum of ST-segment elevation in lead II and V6 $<0.75 \mathrm{~mm}$ for $\mathrm{Cx}$ ) (18), and Aslanger-Bozbeyoğlu criterion (the absence of ST-segment elevation in V2 equal or greater than ST-segment depression in lead $\mathrm{aVL}$ ) for the RCA (19) were calculated. Their diagnostic accuracy was estimated for the general cohort and those with both $\mathrm{Cx}$ and RCA lesions.
Cineangiograms were reviewed by two interventional cardiologists (Ö.Y., E.B.), who were blinded to the electrocardiographic and clinical outcomes. Any disagreement was resolved using the opinion of a third cardiologist (C.Y.K.). Any stenosis $>70 \%$ ( $>50 \%$ for the left main coronary artery) that affected the noninfarct-related arteries was defined as significant in the diagnosis of multivessel disease. For the definition of the infarct-related artery, multiple criteria were used, including angiographic appearance, filling defects suggesting intracoronary thrombus, easiness of guidewire crossing, presence of well-developed collaterals, ECG and troponin trend after opening of the lesion. The patients with both $\mathrm{Cx}$ and RCA lesions were allocated to Group I, while those with lesions in only one of these vessels were allocated to Group II.

\section{Statistical analyses}

The baseline characteristics have been summarized using standard descriptive statistics and compared using chi-square test, Fisher's exact test, and Mann-Whitney U test, as appropriate. The degree of ST-elevation in twelve standard electrocardiographic leads is presented as median and interquartile range values and compared using the Mann-Whitney $\mathrm{U}$ test. The diagnostic power of the individual ECG criteria was assessed using receiver operating characteristics curve analysis; sensitivity, specificity, and c-statistics are presented. The receiver operating characteristics curves were compared using the MedCalc Software [version 18.2.1 (Evaluation version); MedCalc Software, Ostend, Belgium]. All other statistical analyses were performed with SPSS (version 24.0; SPSS Inc., Chicago, IL, USA).

\section{Results}

Total 417 patients with inferior $\mathrm{MI}$ were enrolled during the study period. Ninety-nine patients were excluded because of several reasons, such as left bundle branch block $(n=17)$ and secondary ST-T abnormalities, such as left ventricular hypertrophy $(n=25)$, pre-excitation syndrome $(n=1)$, sub-acute ECG changes $(n=39)$, and history of coronary artery bypass grafting $(n=17)$. Thus, the final study population consisted of 318 patients. Group I had 45 patients (14.2\%); both showed $\mathrm{Cx}$ and RCA lesions on coronary angiograms. Group II included the remaining 273 patients $(85.8 \%)$. Only four patients with acute RCA occlusion had chronic total $\mathrm{Cx}$ occlusion (15.3\%), and three patients with acute Cx occlusion had chronic total RCA occlusion (15.7\%).

Baseline clinical characteristics were summarized in Table 1, along with a comparison of the baseline characteristics according to the presence or absence of both the $\mathrm{Cx}$ and RCA lesions. The degree of ST-segment deviation in the twelve standard electrocardiographic leads did not show any significant difference between the groups (Table 2).

In the whole cohort, Fiol's algorithm (11) had the highest c-statistic; however, the difference between this algorithm 
Table 1. Baseline characteristics*

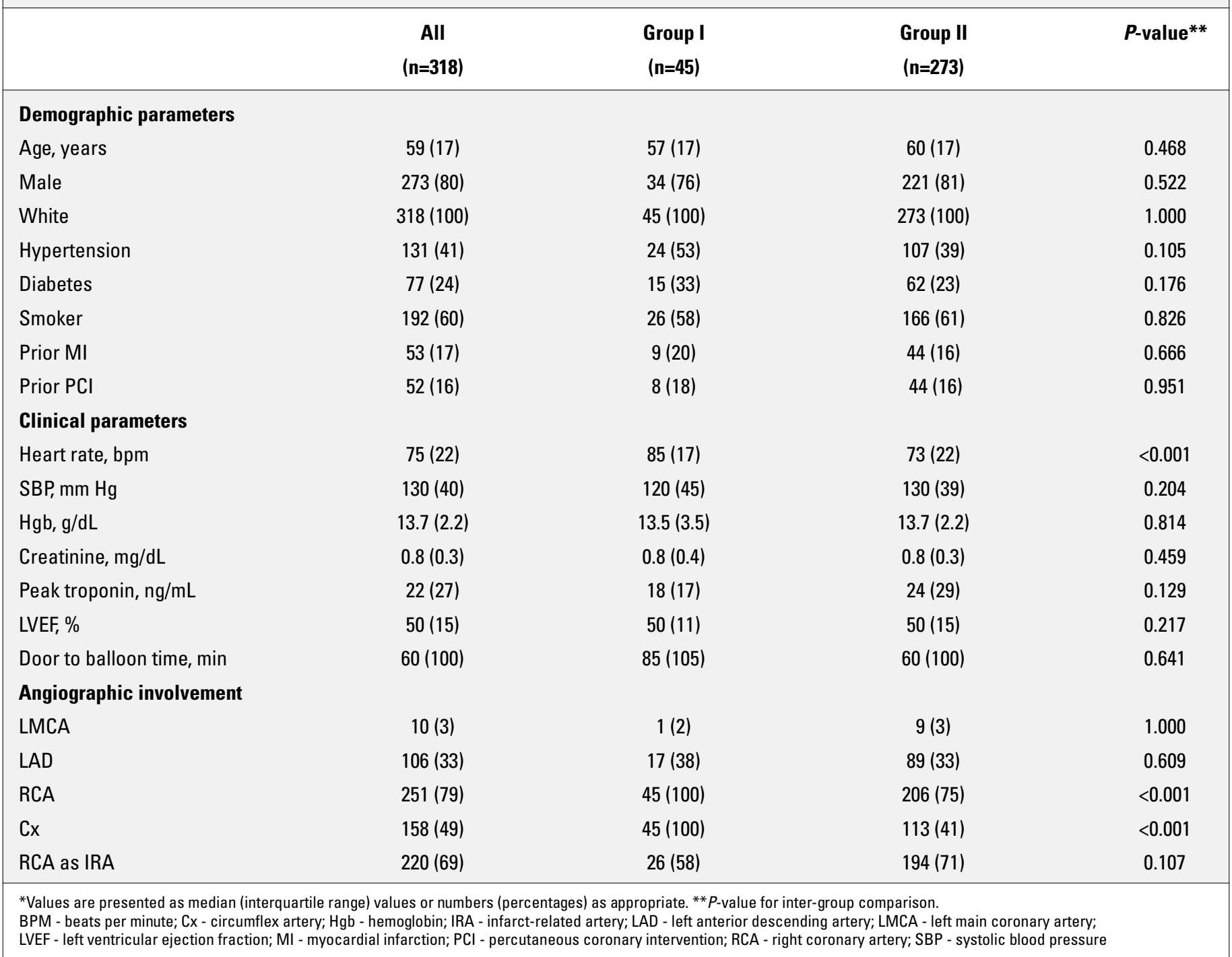

Table 2. The degree of ST-segment deviation in twelve standard electrocardiographic leads*

\begin{tabular}{|lccc|}
\hline & Group I & Group II & $\boldsymbol{P}$-value \\
\hline Lead I, mm & $-0.5(1.0)$ & $-0.5(1.0)$ & 0.490 \\
Lead II, mm & $1.0(1.5)$ & $1.0(1.0)$ & 0.336 \\
Lead III, mm & $1.5(1.1)$ & $1.5(1.0)$ & 0.706 \\
aVR, mm & $0.0(0.5)$ & $0.0(0.5)$ & 0.175 \\
aVL, mm & $-1.0(1.5)$ & $-1.0(1.0)$ & 0.350 \\
aVF, mm & $1.0(1.0)$ & $1.0(1.0)$ & 0.524 \\
V1, mm & $0.0(1.0)$ & $0.0(0.5)$ & 0.413 \\
V2, mm & $-1.0(2.6)$ & $-1.0(1.5)$ & 0.254 \\
V3, mm & $-0.5(1.5)$ & $0.0(1.3)$ & 0.537 \\
V4, mm & $0.0(1.1)$ & $0.0(0.5)$ & 0.179 \\
V5, mm & $0.0(1.1)$ & $0.0(0.5)$ & 0.501 \\
V6, mm & $0.5(1.0)$ & $0.5(1.0)$ & 0.135 \\
\hline *Values are presented as medians (interquartile ranges) & \\
\hline
\end{tabular}

and the following two with the second [Ruiz-Mateoz formula (18); difference between area under curves (AUC) $<0.001 ; 95 \%$ confidence interval (CI) -0.051 to $0.051 ; \mathrm{p}=0.987]$ and the third best c-statistic [Hasdai et al. (4); AUC difference, $0.015 ; 95 \% \mathrm{Cl}$, -0.025 to $0.055 ; p=0.50$ ] was not statistically significant. In patients with both RCA and $\mathrm{Cx}$ disease, the Aslanger-Bozbeyoğlu criterion had the highest c-statistic; however, the difference between this criterion and the following two algorithms with the second [Fiol et al. (11); AUC difference, $0.010 ; 95 \% \mathrm{Cl},-0.144$ to $0.172 ; \mathrm{p}=0.860$ ] and the third highest $\mathrm{c}$-statistic [Almansori et al. (14); AUC difference; $0.045 ; 95 \% \mathrm{Cl},-0.127$ to $0.218 ; p=0.601]$ was not significant. It is noteworthy that our study lacked the required power to detect the subtle differences in the diagnostic accuracies of these criteria. However, the AslangerBozbeyoğlu criterion was the only criterion to reach statistical significance in patients with both RCA and $\mathrm{Cx}$ lesions in this study. The diagnostic accuracy of each individual ECG criteria is presented in Table 3. 
Table 3. Diagnostic performance of the electrocardiographic criteria*

\begin{tabular}{|c|c|c|c|c|c|}
\hline & Sensitivity & Specificity & c-statistic & 95\% Confidence interval & $P$-value \\
\hline \multirow[t]{2}{*}{$\mathrm{V}_{4 \cdot 6} \mathrm{STE}+\mathrm{ST}$ in $\mathrm{I} \geq 0$ (3) } & 88 & 46 & 0.666 & $0.596-0.736$ & $<0.001$ \\
\hline & 81 & 42 & 0.598 & $0.424-0.773$ & 0.272 \\
\hline \multirow{2}{*}{ STD in I+aVL (4) } & 76 & 62 & 0.696 & $0.630-0.762$ & $<0.001$ \\
\hline & 77 & 58 & 0.662 & $0.494-0.831$ & 0.070 \\
\hline \multirow[t]{2}{*}{ STE III>II+STD aVL>I $(5,9,12)$} & 99 & 1 & 0.503 & $0.433-0.573$ & 0.933 \\
\hline & 100 & 0 & 0.500 & $0.325-0.675$ & 1.000 \\
\hline \multirow[t]{2}{*}{$S T D$ in $V_{1-2}(6)$} & 81 & 33 & 0.569 & $0.501-0.636$ & 0.055 \\
\hline & 79 & 38 & 0.609 & $0.441-0.777$ & 0.223 \\
\hline \multirow[t]{2}{*}{ STE II $\geq I I I(7)$} & 44 & 83 & 0.640 & $0.570-0.710$ & $<0.001$ \\
\hline & 37 & 77 & 0.551 & $0.375-0.727$ & 0.567 \\
\hline \multirow[t]{2}{*}{ STE III>II+STE in $V_{1}(7)$} & 14 & 95 & 0.543 & $0.475-0.611$ & 0.230 \\
\hline & 19 & 100 & 0.596 & $0.429-0.763$ & 0.283 \\
\hline \multirow[t]{2}{*}{ STE III>II+STD in I (8) } & 89 & 44 & 0.670 & $0.600-0.740$ & $<0.001$ \\
\hline & 85 & 37 & 0.590 & $0.414-0.765$ & 0.316 \\
\hline \multirow[t]{2}{*}{ STD in aVR $(10,15)$} & 34 & 72 & 0.534 & $0.464-0.605$ & 0.337 \\
\hline & 21 & 73 & 0.476 & $0.302-0.651$ & 0.793 \\
\hline \multirow[t]{2}{*}{ Fiol's algorithm (11) } & 91 & 50 & 0.706 & $0.637-0.775$ & $<0.001$ \\
\hline & 89 & 47 & 0.665 & $0.494-0.835$ & 0.066 \\
\hline \multirow[t]{2}{*}{ Tierala's algorithm (13) } & 81 & 45 & 0.634 & $0.564-0.704$ & $<0.001$ \\
\hline & 73 & 37 & 0.532 & $0.356-0.708$ & 0.720 \\
\hline \multirow[t]{2}{*}{ Almansori's scoring system (14) } & 80 & 57 & 0.685 & $0.617-0.752$ & $<0.001$ \\
\hline & 77 & 53 & 0.635 & $0.463-0.806$ & 0.133 \\
\hline \multirow[t]{2}{*}{ Huang's algorithm (17) } & 82 & 44 & 0.635 & $0.565-0.706$ & $<0.001$ \\
\hline & 77 & 37 & 0.551 & $0.375-0.727$ & 0.567 \\
\hline \multirow[t]{2}{*}{ Ruiz-Mateos formula (18) } & 83 & 57 & 0.706 & $0.639-0.773$ & $<0.001$ \\
\hline & 73 & 44 & 0.588 & $0.413-0.762$ & 0.328 \\
\hline \multirow[t]{2}{*}{ Aslanger-Bozbeyoğlu criterion (19) } & 80 & 48 & 0.650 & $0.581-0.720$ & $<0.001$ \\
\hline & 81 & 58 & 0.709 & $0.547-0.872$ & 0.019 \\
\hline
\end{tabular}

\section{Discussion}

More than $50 \%$ of the patients with STEMI referred for $\mathrm{pPCl}$ have critical stenoses in their non-infarct-related arteries (20), including chronic total occlusions in $10 \%-15 \%(21,22)$. This may cause a diagnostic problem in patients with inferior STEMI when coronary angiography reveals total occlusion or suspicious-looking lesions in both the RCA and Cx. Failure to re-vascularize the real acute lesion leads to dire consequences; however, the angiographic appearance may not always be completely reliable. Although many algorithms have been developed to identify the infarct-related artery in patients with inferior STEMI, these studies have examined a random group of patients, and many studies excluded patients with multives- sel disease (3-19). Therefore, it is unclear whether these algorithms have the discriminative power to identify the real culprit lesion in patients with critical stenosis in both the coronary arteries.

Our results indicate that many of the current criteria and algorithms lose their predictive power when both the coronary arteries supplying the inferior wall show critical stenosis. This may be due to a widespread ischemic area or cancellation of the ischemic vectors. From an electrocardiographic perspective, the essential difference between the RCA and Cx occlusion is the spatial orientation of the myocardium and its injury vector. The myocardium subtended by the RCA is located more rightward and anteriorly, while the myocardium subtended by $\mathrm{Cx}$ is more posterior and leftward (7). Therefore, the algorithms or 
criteria that combine frontal and horizontal plane information would be superior to the ones that do not include information from both these planes. We also believe that combining these two criteria that have information from the same spatial plane is generally unnecessary and does not increase the diagnostic accuracy. Accordingly, a recently published criterion by our group, that used the information from two spatial planes identified the culprit artery with a reasonably good sensitivity and specificity in patients with inferior STEMI and critical stenoses in both the $\mathrm{RCA}$ and the Cx. It is noteworthy that this criterion is reportedly able to identify which of the right and left coronary system is the culprit in patients who present with both inferior and anterior ST-segment elevation (19). In the current study, it emerged as the only statistically significant criterion in patients with both $\mathrm{RCA}$ and $\mathrm{Cx}$ stenosis and showed an increased diagnostic accuracy in patients with inferior STEMI and critical stenoses in both $\mathrm{RCA}$ and $\mathrm{Cx}$ than in the whole population with inferior STEMI. Although external validation is required, this interventionalistfriendly criterion appears to be valuable in situations where infarct-related territory or artery are in question on the basis of angiographic images (Fig. 1).

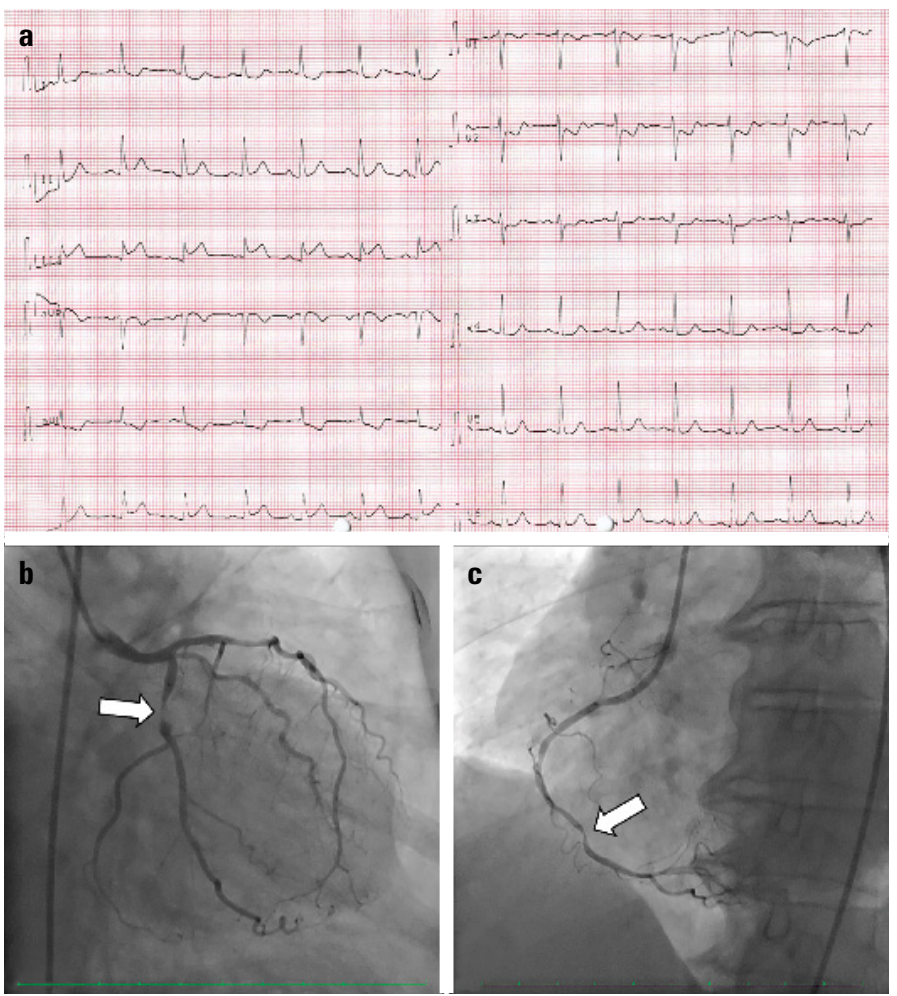

Figure 1. (a) The electrocardiogram of a 65-year-old woman who presented with inferior myocardial infarction. Fiol's algorithm identifies the right coronary artery (RCA) as the infarct-related artery; the angiogram showed that both the circumflex coronary artery $(\mathrm{Cx}$, (b) and the right coronary artery (RCA, (c) had critical lesions. Without thrombotic appearance of the $\mathrm{Cx}$ lesion in this case, it might be difficult to identify the infarct-related artery because both the arteries show comparable stenoses with similar distal run-offs. The AslangerBozbeyoğlu criterion also indicates $\mathrm{Cx}$ as the infarct-related artery. The Cx artery was opened and stented

\section{Study limitations}

Our study has certain limitations. It is a retrospective study, with all known limitations associated with bias. Standard lead placement could not be confirmed. Not all the criteria analyzed in this study were specifically designed for the identification of the RCA or the Cx as the culprit artery. Some of these criteria $(3,4,6,10,15)$ only aimed to determine the presence of occlusion in a specific artery, and the absence of lesion in one artery would not automatically confirm its presence in the other artery. Furthermore, the sample size of patients with both Cx and RCA lesion was relatively low; therefore, some criteria might not have been able to reach statistical significance despite having an actual diagnostic power in this subgroup. Dual total occlusion was underrepresented in our population; therefore, our results may not apply for both RCA and Cx total occlusions, one acute, and the other chronic. In addition, the diagnostic accuracy of conventional coronary angiography for atherothrombosis is poor; therefore, the definitions of the culprit lesion may differ among interventionalists.

\section{Conclusion}

In conclusion, the Aslanger-Bozbeyoğlu criterion is not only helpful in differentiating the infarct territory in combined inferior and anterior ST-segment elevation as previously shown, 19 but also is valuable in identifying the infarct-related artery in patients with inferior STEMI and critical lesions in both the RCA and $\mathrm{Cx}$. If these results to be externally validated, the AslangerBozbeyoğlu criterion can be used as an interventionalist-friendly tool in determining the culprit lesion for intervention in patients with STEMI.

Acknowledgements: We would like to thank to Beril Balak for her valuable support.

Conflict of interest: None declared.

Peer-review: Externally peer-reviewed.

Authorship contributions: Concept - E.A., M.A.S..; Design - E.A.; Supervision - E.B., M.M.D.; Fundings - None; Materials - None; Data collection and/or processing - Ö.Y., B.Ş., Y.S.A.; Analysis and/or interpretation - E.A.; Literature search - Ö.Y., E.A.; Writing - E.A.; Critical review - C.Y.K., M.M.D.

\section{References}

1. Berger PB, Ryan TJ. Inferior myocardial infarction. High-risk subgroups. Circulation 1990; 81: 401-11. [CrossRef]

2. Correale E, Battista R, Martone A, Pietropaolo F, Ricciardiello V, DiGirolamo $D$, et al. Electrocardiographic patterns in acute inferior myocardial infarction with and without right ventricle involvement: classification, diagnostic and prognostic value, masking effect. Clin Cardiol 1999; 22: 37-44. [CrossRef] 
3. Bairey CN, Shah PK, Lew AS, Hulse S. Electrocardiographic differentiation of occlusion of the left circumflex versus the right coronary artery as a cause of inferior acute myocardial infarction. Am J Cardiol 1987; 60: 456-9. [CrossRef]

4. Hasdai D, Birnbaum Y, Herz I, Sclarovsky S, Mazur A, Solodky A. ST segment depression in lateral limb leads in inferior wall acute myocardial infarction. Implications regarding the culprit artery and the site of obstruction. Eur Heart J 1995; 16: 1549-53. [CrossRef]

5. Herz I, Assali AR, Adler Y, Solodky A, Sclarovsky S. New electrocardiographic criteria for predicting either the right or left circumflex artery as the culprit coronary artery in inferior wall acute myocardial infarction. Am J Cardiol 1997; 80: 1343-5. [CrossRef]

6. Kontos MC, Desai PV, Jesse RL, Ornato JP. Usefulness of the admission electrocardiogram for identifying the infarct-related artery in inferior wall acute myocardial infarction. Am J Cardiol 1997; 79: 182-4. [CrossRef]

7. Zimetbaum PJ, Krishnan S, Gold A, Carrozza JP 2nd, Josephson ME. Usefulness of ST-segment elevation in lead III exceeding that of lead II for identifying the location of the totally occluded coronary artery in inferior wall myocardial infarction. Am J Cardiol 1998; 81: 918-9. [CrossRef]

8. Chia BL, Yip JW, Tan HC, Lim YT. Usefulness of ST elevation II/III ratio and ST deviation in lead I for identifying the culprit artery in inferior wall acute myocardial infarction. Am J Cardiol 2000; 86: 341-3. [CrossRef]

9. Kabakci G, Yildirir A, Yildiran L, Batur MK, Cagrikul R, Onalan 0, et al. The diagnostic value of 12-lead electrocardiogram in predicting infarct-related artery and right ventricular involvement in acute inferior myocardial infarction. Ann Noninvasive Electrocardiol 2001; 6: 229-35. [CrossRef]

10. Nair R, Glancy DL. ECG discrimination between right and left circumflex coronary arterial occlusion in patients with acute inferior myocardial infarction: value of old criteria and use of lead aVR. Chest 2002; 122: 134-9. [CrossRef]

11. Fiol M, Cygankiewicz I, Carrillo A, Bayés-Genis A, Santoyo O, Gómez $A$, et al. Value of electrocardiographic algorithm based on "ups and downs" of ST in assessment of a culprit artery in evolving inferior wall acute myocardial infarction. Am J Cardiol 2004; 94: 709-14.

12. Verouden NJ, Barwari K, Koch KT, Henriques JP, Baan J, van der Schaaf RJ, et al. Distinguishing the right coronary artery from the left circumflex coronary artery as the infarct related artery in patients undergoing primary percutaneous coronary intervention for acute inferior myocardial infarction. Europace 2009; 11: 1517-21.
13. Tierala I, Nikus KC, Sclarovsky S, Syvänne M, Eskola M; HAAMU Study Group. Predicting the culprit artery in acute ST-elevation myocardial infarction and introducing a new algorithm to predict infarct-related artery in inferior ST-elevation myocardial infarction: correlation with coronary anatomy in the HAAMU Trial. J Electrocardiol 2009; 42: 120-7. [CrossRef]

14. Almansori M, Armstrong P, Fu Y, Kaul P. Electrocardiographic identification of the culprit coronary artery in inferior wall ST elevation myocardial infarction. Can J Cardiol 2010; 26: 293-6. [CrossRef]

15. Kanei Y, Sharma J, Diwan R, Sklash R, Vales LL, Fox JT, et al. STsegment depression in aVR as a predictor of culprit artery and infarct size in acute inferior wall ST-segment elevation myocardial infarction. J Electrocardiol 2010; 43: 132-5. [CrossRef]

16. Taglieri N, Saia F, Alessi L, Cinti L, Reggiani ML, Lorenzini M, et al. Diagnostic performance of standard electrocardiogram for prediction of infarct related artery and site of coronary occlusion in unselected STEMI patients undergoing primary percutaneous coronary intervention. Eur Heart J Acute Cardiovasc Care 2014; 3: 326-39. [CrossRef]

17. Huang X, Ramdhany SK, Zhang Y, Yuan Z, Mintz GS, Guo N. New ST-segment algorithms to determine culprit artery location in acute inferior myocardial infarction. Am J Emerg Med 2016; 34: 1772-8.

18. Ruiz-Mateos B, García-Borbolla R, Nunez-Gil I, Almendro-Delia M, Vivas D, Seoane-García $T$, et al. Identification of the culprit artery in inferior myocardial infarction through the 12-lead ECG. Coron Artery Dis 2020; 31: 20-26. [CrossRef]

19. Bozbeyoğlu E, Aslanger E, Yıldırımtürk Ö, Şimşek B, Karabay CY, Türer $A$, et al. An algorithm for the differentiation of the infarct territory in difficult to discern electrocardiograms. J Electrocardiol 2018; 51: 1055-60. [CrossRef]

20. Park DW, Clare RM, Schulte PJ, Pieper KS, Shaw LK, Califf RM, et al. Extent, location, and clinical significance of non-infarct-related coronary artery disease among patients with ST-elevation myocardial infarction. JAMA 2014; 312: 2019-27. [CrossRef]

21. Claessen BE, Dangas GD, Weisz G, Witzenbichler B, Guagliumi G, Möckel $M$, et al. Prognostic impact of a chronic total occlusion in a non-infarct-related artery in patients with ST-segment elevation myocardial infarction: 3 -year results from the HORIZONS-AMI trial. Eur Heart J 2012; 33: 768-75. [CrossRef]

22. Råmunddal $T$, Hoebers LP, Henriques JP, Dworeck C, Angerås 0 , Odenstedt J, et al. Chronic total occlusions in Sweden--a report from the Swedish Coronary Angiography and Angioplasty Registry (SCAAR). PLoS One 2014; 9: e103850. [CrossRef] 